\title{
The impact of the stairs to the earthquake resistance of reinforced concrete frame structure
}

\author{
Cuifang $\mathrm{Xu}^{1, \mathrm{a}}$, Tieying $\mathrm{Li}^{2, \mathrm{~b}}$ \\ ${ }^{1}$ Architecture and Civil Engineering College, Taiyuan University of Technology, \\ Taiyuan,Shanxi,030024,China \\ ${ }^{2}$ Architecture and Civil Engineering College, Taiyuan University of Technology, \\ Taiyuan,Shanxi,030024, China \\ axucuifang9421@163.com, 'Ity680412@163.com
}

Keywords: staircase; reinforced concrete; frame structure; seismic performance; SAP2000

\begin{abstract}
In order to study the mechanical performance and the overall performance of the reinforced concrete frame structure with stairs under the earthquake action, this paper uses SAP2000 to model the reinforced concrete frame structure with and without staircase, calculate elastic seismic response of the models by response spectrum method and bottom shear method. The results show that the stairs have significant influence on the seismic lateral stiffness, vibration mode and internal force of frame beam column of the reinforced concrete frame structure.
\end{abstract}

\section{Introduction}

In traditional seismic design of frame structure, the effect of staircase is often overlooked ,however in the Wenchuan earthquake, stairs did not give full play to its role as an important way of escape evacuation but even cause the damage of connected components more serious than body ${ }^{[1-2]}$. After the Wenchuan earthquake, the "code for seismic design of buildings" ${ }^{[3]}$ (GB50011-2010) were partially revised by China Academy of Building Research and the relevant units. According to section 3.6.6 of the code, the seismic analysis of structures by computer should meet the following requirements: establishment of computation model, the necessary simplified calculation and processing should be consistent with the actual working condition of structure, should be considered the influence of staircase construction in calculation .This paper compare and analysis the two frame structures included and not included the stairs.

\section{Analysis model and parameters}

Based on the design concept of the structure and the existing research results, the types and shapes of the structure, the number and location of stairs in the structure have significant impact on seismic performance of structure ${ }^{[4-5]}$. This paper compare and analysis the two reinforced concrete frame structures included and not included the stairs. In order to minimize the interference factors, highlighting the seismic effect of the stairs on monolithic structure, establish two models of regular, simple, continuous gallery structure ${ }^{[6]}$. To avoid the torsion of the overall structure in seismic process caused by the asymmetric location of the stairs, the stairs in the model containing the stairs only symmetrically arranged on two sides of the structure and bench plates arranged along the Y-axis direction.

Model 1 ( M-1) is a cast-in-place reinforced concrete structure with six layers, the height is 3.0m, width is $4.8 \mathrm{~m}$, depth is $6.0 \mathrm{~m}, 2.4 \mathrm{~m}$ and $6.0 \mathrm{~m}$ respectively. Sectional dimensions of main components : sectional dimensions of frame column is $500 \mathrm{~mm} \times 600 \mathrm{~mm}$, Sectional dimensions of bidirectional layout frame beam is $300 \mathrm{~mm} \times 700 \mathrm{~mm}$, thickness of floor is $100 \mathrm{~mm}$. Take concrete strength grade of frame columns as C40, other components as C30.

Model 2 (M-2) add additional double stairs in the two terminal of plane column grid (1) - (2)and CD, JK-axis)on the basis of model 1( M-1 ). The model use Y- direction wobble plate instead of 
bench plate and the width of bench plate is $2.4 \mathrm{~m}$. Add additional staircase stair plaform in the vertical layer and the thickness of bench plate and stair plaform is $160 \mathrm{~mm}$, sectional dimensions of platform beam is $250 \mathrm{~mm} \times 350 \mathrm{~mm}$, stair column is $250 \mathrm{~mm} \times 350 \mathrm{~mm}$.

The stair wobble plate and beach board use shell elements to simulate, beam and column (including stair column and stair beam) use link element to simulate ; Each model in the analysis set restraint at direction of X, Y, Z .As shown in Figure 1.
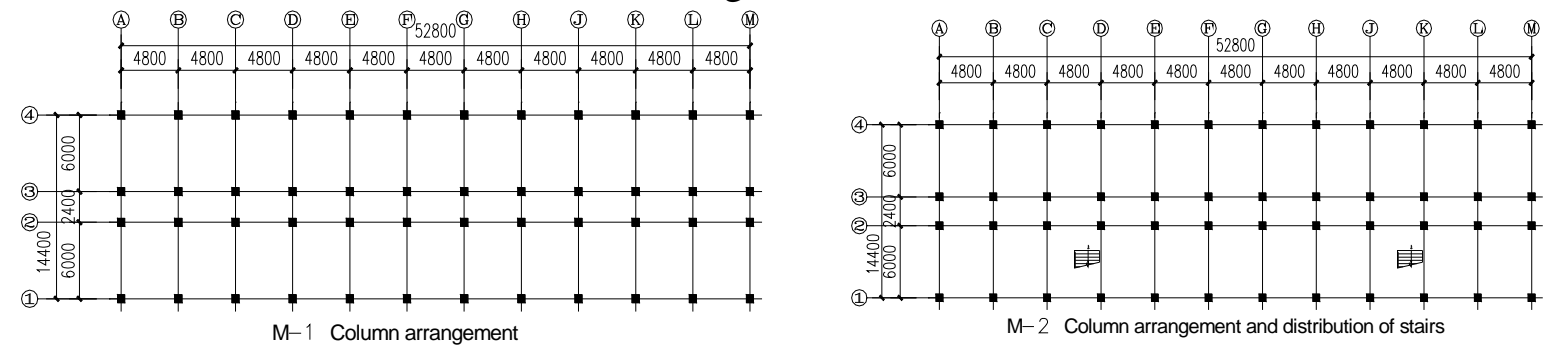

Fig.1 Planar graph of models

\section{The set of calculation conditions}

Setting floor live load standards at a value of $2 \mathrm{kN} / \mathrm{m}^{2}$, no-exalted roof live load standard at a value of $0.5 \mathrm{kN} / \mathrm{m}^{2}$, the floor additional dead-load standard at a value of $2.5 \mathrm{kN} / \mathrm{m}^{2}$; seven degrees seismic fortification intensity, and earthquake group as the second group, II class venues, (Ts=0.4s).

\section{Analysis of calculation}

\section{Vibration mode analysis of calculation}

This paper use Ritz vector method for vibrational mode analysis to obtain larger mass participation factor so as to facilitate comparison; Take maximum vibration mode number of the structure as 12 , target dynamic load participation ratio as $99 \%$; Structural damping ratio as 0.05 ; Model combinations use the CQC method and direction combined use the SRSS method.

(1) Under the condition of response spectrum, the period and the mass participation factor ( Ux, $\mathrm{Uy}, \mathrm{Rx}, \mathrm{Ry}$ and $\mathrm{Rz}$ are parameters along the global coordinates $\mathrm{X}, \mathrm{Y}$ direction and around the $\mathrm{X}$ axis, $\mathrm{Y}$ axis, $\mathrm{Z}$ axis direction) of the first 5 vibration mode in every model as shown in table 1 to table 2.

Table 1 :Modal Participating Mass Ratios of Mode(1 5)of M-1

\begin{tabular}{|l|c|c|c|c|c|c|}
\hline StepType & Period(s) & $\mathrm{U}_{\mathrm{x}}$ & $\mathrm{U}_{\mathrm{y}}$ & $\mathrm{R}_{\mathrm{x}}$ & $\mathrm{R}_{\mathrm{y}}$ & $\mathrm{R}_{\mathrm{z}}$ \\
\hline Mode-1 & 0.500629 & 0.00000 & 0.81494 & 0.63794 & $5.634 \mathrm{E}-07$ & 0.55588 \\
\hline Mode-2 & 0.495593 & 0.83156 & 0.00000 & $3.821 \mathrm{E}-19$ & 0.12319 & 0.06033 \\
\hline Mode-3 & 0.471058 & 0.00483 & 0.00000 & 0.00000 & 0.00076 & 0.20063 \\
\hline Mode-4 & 0.161852 & 0.09838 & $5.908 \mathrm{E}-17$ & $7.074 \mathrm{E}-15$ & 0.00093 & 0.00664 \\
\hline Mode-5 & 0.159231 & $3.126 \mathrm{E}-20$ & 0.11075 & 0.00248 & $3.933 \mathrm{E}-06$ & 0.07554 \\
\hline
\end{tabular}

Table 2 :Modal Participating Mass Ratios of Mode(1 5)of M-2

\begin{tabular}{|l|c|c|c|c|c|c|}
\hline StepType & Period(s) & $\mathrm{U}_{\mathrm{x}}$ & $\mathrm{U}_{\mathrm{y}}$ & $\mathrm{R}_{\mathrm{x}}$ & $\mathrm{R}_{\mathrm{y}}$ & $\mathrm{R}_{\mathrm{z}}$ \\
\hline Mode-1 & 0.444239 & 0.63605 & 0.01884 & 0.01526 & 0.09462 & 0.07600 \\
\hline Mode-2 & 0.429346 & 0.00665 & 0.78527 & 0.62845 & 0.00096 & 0.67389 \\
\hline Mode-3 & 0.411987 & 0.17933 & 0.00631 & 0.00488 & 0.02719 & 0.06073 \\
\hline Mode-4 & 0.149015 & 0.08584 & 0.00883 & 0.00066 & 0.00061 & 0.00116 \\
\hline Mode-5 & 0.143312 & 0.00430 & 0.09666 & 0.00209 & $7.867 \mathrm{E}-05$ & 0.10214 \\
\hline
\end{tabular}

Table 1 and table 2 show as follow: (1)In the model 1, the first and second mode of vibration is mainly translational along the direction of $\mathrm{Y}$ and $\mathrm{X}$. The third mode of vibration is mainly rotational around the direction of $\mathrm{Z}$. The result shows that the structure is bidirectional regular and structural torsion is not obvious; In the model 2, the first, second and third mode of vibration is mainly translational along the direction of $\mathrm{X}, \mathrm{Y}$ and $\mathrm{X}$ respectively. The third mode of vibration is mainly 
rotational around the direction of Z. (2) The first translational period of model 2 is much shorter than that of model 1 . The period reduce to $89.6 \%$ along $X$ direction, this change reflects the participation of the stairs changed the structural vibration modes, and significantly increased the stiffness of the structure in the X-direction ( vertical bench plates) . (3)The first order vibration mode of Model 1 and Model 2 is mainly translational along the $\mathrm{Y}$-direction and X-direction respectively ,this change reflects that the participation of the stairs changed the structural vibration modes , and significantly increased the stiffness of the structure in the Y-direction ( along the bench plates) .

(2)Under the condition of response spectrum, the internal force of frame beam-column in the lower part of structure is bigger than that of the upper part, therefore, take its maximum internal force of the structure for comparative analysis.

1)Under the condition of response spectrum, Select the section internal forces of the corner column and frame column which connected with the stair in each model(1) $\times$ C 、 (1) $\times$ A axis) to do comparative analysis, the internal forces are shown in table 3.

Table 3 The internal forces of columns (1) $\times$ C 、 (1) $\times$ A axis)in first floor and the second floor under the condition of response spectrum

\begin{tabular}{|c|c|c|c|c|c|c|c|c|c|}
\hline \multirow{3}{*}{\multicolumn{2}{|c|}{ model name }} & \multicolumn{4}{|c|}{ (1) $\times$ A } & \multicolumn{4}{|c|}{ (1) $\times$ C } \\
\hline & & \multicolumn{2}{|c|}{ first floor } & \multicolumn{2}{|c|}{ second floor } & \multicolumn{2}{|c|}{ first floor } & \multicolumn{2}{|c|}{ second floor } \\
\hline & & $\begin{array}{l}\text { under } \\
\text { column } \\
\text { section }\end{array}$ & $\begin{array}{l}\text { column } \\
\text { section }\end{array}$ & $\begin{array}{l}\text { under } \\
\text { column } \\
\text { section }\end{array}$ & $\begin{array}{l}\text { column } \\
\text { section }\end{array}$ & $\begin{array}{l}\text { under } \\
\text { column } \\
\text { section }\end{array}$ & $\begin{array}{l}\text { column } \\
\text { section }\end{array}$ & $\begin{array}{c}\text { under } \\
\text { column } \\
\text { section }\end{array}$ & $\begin{array}{l}\text { column } \\
\text { section }\end{array}$ \\
\hline \multirow{3}{*}{ M-1 } & $\begin{array}{c}\text { shear } \\
\text { force }(\mathrm{kN})\end{array}$ & \multicolumn{2}{|c|}{70.42} & \multicolumn{2}{|c|}{51.66} & \multicolumn{2}{|c|}{88.87} & \multicolumn{2}{|c|}{86.65} \\
\hline & axial force $(\mathrm{kN})$ & \multicolumn{2}{|c|}{229.52} & \multicolumn{2}{|c|}{171.63} & \multicolumn{2}{|c|}{8.47} & \multicolumn{2}{|c|}{6.77} \\
\hline & $\begin{array}{c}\text { bending } \\
\text { moment }(\mathrm{kN} \cdot \mathrm{m})\end{array}$ & 141.81 & 169.49 & 76.72 & 78.29 & 159.52 & 107.10 & 130.27 & 129.70 \\
\hline \multirow{3}{*}{ M-2 } & $\begin{array}{c}\text { shear } \\
\text { force }(\mathrm{kN})\end{array}$ & \multicolumn{2}{|c|}{44.31} & \multicolumn{2}{|c|}{36.98} & 51.41 & 67.49 & 61.61 & 57.73 \\
\hline & axial force $(\mathrm{kN})$ & \multicolumn{2}{|c|}{205.77} & \multicolumn{2}{|c|}{158.94} & 489.83 & 478.71 & 326.07 & 294.38 \\
\hline & $\begin{array}{c}\text { bending } \\
\text { moment }(\mathrm{kN} \cdot \mathrm{m})\end{array}$ & 42.11 & 90.85 & 54.96 & 56.05 & 68.69 & 97.59 & 85.51 & 88.48 \\
\hline
\end{tabular}

It can be seen from Table 3 : (1)in M-1 which contains no stairs, the shear force of the column which connected with the stair is bigger than that of the corner colum ,but the axial force of the former is much smaller than that of the latter. (2), the maximum axial force of the column which connected with the stair in M-2 which contain stairs is 58 times bigger than that of the M-2 ,but its shear force and bending moment is correspondingly decreasing than that of $\mathrm{M}-1$. (3)comparing the internal forces of corner column in the two model, we can see that the axial force, shear force and bending moment in $\mathrm{M}-2$ are all smaller than that of $\mathrm{M}-1$.

2)Under the condition of response spectrum, When $Z=3.0 \mathrm{~m}$ and $\mathrm{Z}=6.0 \mathrm{~m}$, select the frame beams which between axes A,C and axes (1)-(2), the internal forces of these frame beams are shown in Table 4.

Table 4 The internal forces of frame beams which between axes A,C and axes (1)-(2) under the condition of response spectrum

\begin{tabular}{|c|c|c|c|c|c|}
\hline \multicolumn{3}{|c|}{ model name } & $\begin{array}{c}\text { shear } \\
\text { force }(\mathrm{kN})\end{array}$ & torque $(\mathrm{kN} \cdot \mathrm{m})$ & bending moment $(\mathrm{kN} \cdot \mathrm{m})$ \\
\hline \multirow{6}{*}{ M-1 } & \multirow{2}{*}{ 1th beam } & $Y=0$ & \multirow{2}{*}{3.06} & \multirow{2}{*}{0.08} & 9.75 \\
\hline & & $Y=6$ & & & 8.61 \\
\hline & \multirow{2}{*}{ 130th beam } & $\mathrm{Y}=0$ & \multirow{2}{*}{3.33} & \multirow{2}{*}{0.08} & 10.47 \\
\hline & & $Y=6$ & & & 9.51 \\
\hline & \multirow{2}{*}{ 7th beam } & $\mathrm{Y}=0$ & \multirow{2}{*}{1.94} & \multirow{2}{*}{0.05} & 6.20 \\
\hline & & $Y=6$ & & & 5.43 \\
\hline
\end{tabular}




\begin{tabular}{|c|c|c|c|c|c|}
\hline & \multirow{2}{*}{ 136th beam } & $Y=0$ & \multirow{2}{*}{2.10} & \multirow{2}{*}{0.06} & 6.63 \\
\hline & & $Y=6$ & & & 5.99 \\
\hline \multirow{8}{*}{ M-2 } & \multirow{2}{*}{ 50th beam } & $\mathrm{Y}=0$ & \multirow{2}{*}{19.08} & \multirow{2}{*}{0.45} & 60.83 \\
\hline & & $Y=6$ & & & 53.62 \\
\hline & \multirow{2}{*}{ 178th beam } & $\mathrm{Y}=0$ & \multirow{2}{*}{20.49} & \multirow{2}{*}{0.48} & 64.39 \\
\hline & & $Y=6$ & & & 58.53 \\
\hline & \multirow{2}{*}{ 55th beam } & $Y=0$ & 162.52 & 6.79 & 163.77 \\
\hline & & $Y=6$ & 104.29 & 5.15 & 111.06 \\
\hline & \multirow{2}{*}{ 183th beam } & $\mathrm{Y}=0$ & 140.31 & 6.04 & 149.38 \\
\hline & & $\mathrm{Y}=6$ & 125.97 & 6.87 & 127.52 \\
\hline
\end{tabular}

It can be seen from Table 4: as stairs participating in seismic response of overall frame structures , The shear force ,bending moment and torque of the frame beams in its over-all structure has increased significantly than that of the frame structure contained no stairs, especially the internal forces of the frame beams which connected to the stairs increase more obvious .The increase of the beam shear ,bending moment is very obvious .therefore,the stairs can't be ignored in seismic design of the over-all structure.

\section{Comparison of the bottom shear method calculation results}

(1)Under the condition of the X-direction, Y-direction earthquake action $\left(\mathrm{Q}_{\mathrm{x}}, \mathrm{Q}_{\mathrm{y}}\right)$, In the model, the internal force of the column(located in (1) $\times \mathrm{C}$ axis) in the second floor and the frame beam between the frame columns along the bench plates is shown in table 5 and table 6 .

Table 5 The axial force of the column(located in(1) $\times \mathrm{C}$ axis) in the second floor under the condition of $\mathrm{Q}_{\mathrm{x}}, \mathrm{Q}_{\mathrm{y}}$

\begin{tabular}{|c|c|c|c|c|c|}
\hline \multirow{2}{*}{\multicolumn{2}{|c|}{ model name }} & \multicolumn{3}{|c|}{$1 \mathrm{C}$} \\
\cline { 3 - 6 } & \multicolumn{2}{|c|}{$\mathrm{Q}_{\mathrm{x}}$} & \multicolumn{2}{c|}{$\mathrm{Q}_{\mathrm{y}}$} \\
\cline { 3 - 6 } & $\begin{array}{c}\text { under column } \\
\text { section }\end{array}$ & $\begin{array}{c}\text { column } \\
\text { section }\end{array}$ & $\begin{array}{c}\text { under column } \\
\text { section }\end{array}$ & $\begin{array}{c}\text { column } \\
\text { section }\end{array}$ \\
\hline $\mathrm{M}-1$ & $\begin{array}{c}\text { axial } \\
\text { force }(\mathrm{kN})\end{array}$ & -3.42 & -3.74 & 168.09 & 210.80 \\
\cline { 3 - 6 } $\mathrm{M}-2$ & 258.27 & 437.73 & 398.28 & 630.29 \\
\hline
\end{tabular}

Table 6 The bending moment of frame beam between the frame columns along the bench plates under the condition of $\mathrm{Q}_{\mathrm{x}}, \mathrm{Q}_{\mathrm{y}}$

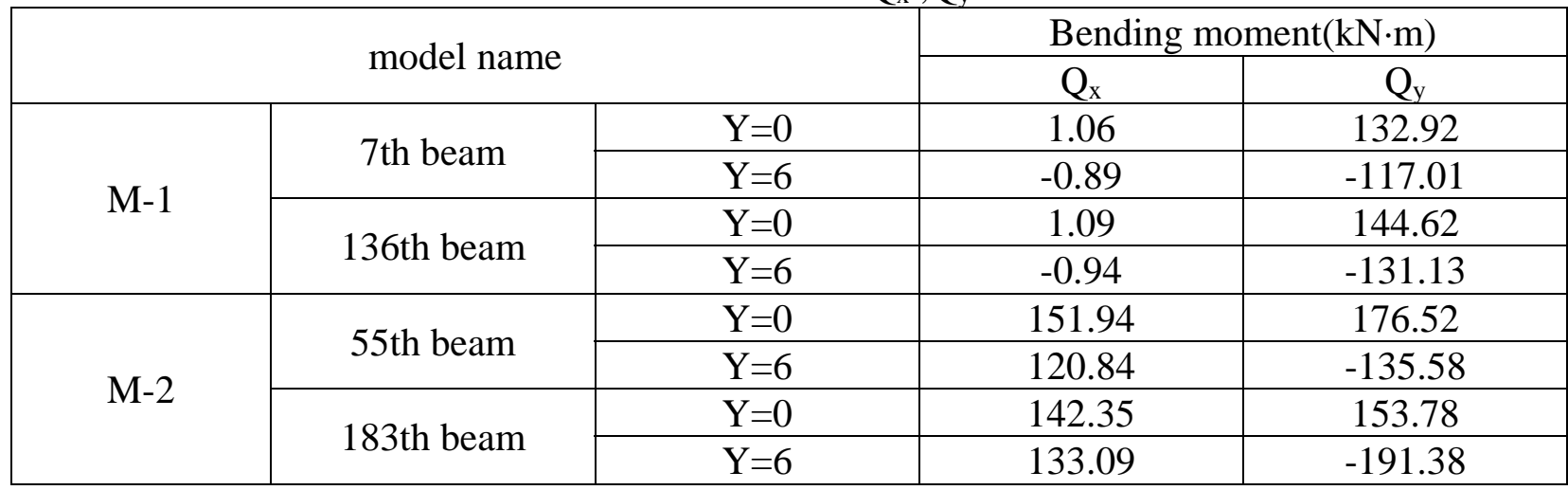

It can be seen from Table 5 and Table 6: (1)The bending moment at the end of the beam which connected with the stair components and the pressure of correspondingly columns in $\mathrm{M}-2$ has increased significantly than that of M-1. (2)The internal forces of correspondingly components under $\mathrm{Q}_{\mathrm{y}}$ has increased significantly than that of $\mathrm{Q}_{\mathrm{x}}$ in each model, and the change of internal forces in $\mathrm{M}-1$ is more obvious. It also shows that stairs has greatly increased the lateral stiffness of the structure in Y-direction

\section{Conclusion}


(1)Stairs have a significant contribution to the bidirectional lateral stiffness of the structure , and the enhancement of the lateral stiffness along the beach plate is more obvious than the enhancement of vertical lateral stiffness 。 Stairs participating in the overall structure calculation may cause the torsion effects of the original structure more unconspicuous.

(2)When the stairs participating in the structure overall calculation, the internal force change of the stair itself and overall structure is relatively larger ,especially the internal force change of stair and beam column connecting with the stair is more obvious. Suggest that when we design the location, number and direction of stairs, we should not only consider the building use, but also should notice the significantly impact of stairs on the earthquake effect of overall structure, Adjust combining with the structure calculation, ensure that stairs can serve as evacuation passageway.

(3)In view of the complexity of the earthquake action and structural response, as well as the current limitations of the calculation software, so needed to carry out a experiment investigation on the seismic response of steel-concrete frame structure with stairs to more comprehensively and objectively show the impacting mechanism of the stairs on the overall structure seismic performance.

\section{Acknowledgements}

This research is supported by National Natural Science Foundation of China (No. 50978178). The corresponding author is Tieying Li. We are very grateful to all the reviewers for their constructive comments on this paper.

\section{References}

[1] Editorial Committee of Analytical Reports About Disaster Investigation and Reconstruction of Architecture Subjected to Wenchuan Earthquake. Analytical Reports About Disaster Investigation and Reconstruction of Architecture Subjected to Wenchuan Earthquake[M]. Beijing: China Architecture and Building Press, 2008(In Chinese).

[2] Yingxiong Wu, Ying Huang. Wenchuan Earthquake Disaster Initiation Construction Structural Design Ponder[J]. Fujian Architecture \& Construction,2008,124(10):90-95(In Chinese).

[3] GB 50011-2010 Code for seismic design of buildings [S].Beijing China Architecture \& Building Press, 2010(In Chinese).

[4] Kaihai Luo, Yayong Wang, Qiong Zuo .Analysis on action effects of stairs in RC frame structures under earthquake[J].Building Structure,Vol.41(11)(2011), p.88.(In Chinese).

[5] Yuan Feng, Xiaobin Wu , Congchun Li , Yaoqing Xiong . A study of the earthquake-resistance performance of frames with staircases[J]. CHINA CIVIL ENGINEERING JOURNAL, Vol. 43(10) (2010), p.53. (In Chinese).

[6] Hongjun Dai, Ai Qi. Analysis on seismic-response of reinforced concrete frame structure with staircase[J].Journal of Fuzhou University (Natural Science), Vol.38 (2)(2010), p.259.(In Chinese). 